\title{
Total Synthesis of (-)-Flueggine A and (+)-Virosaine B
}

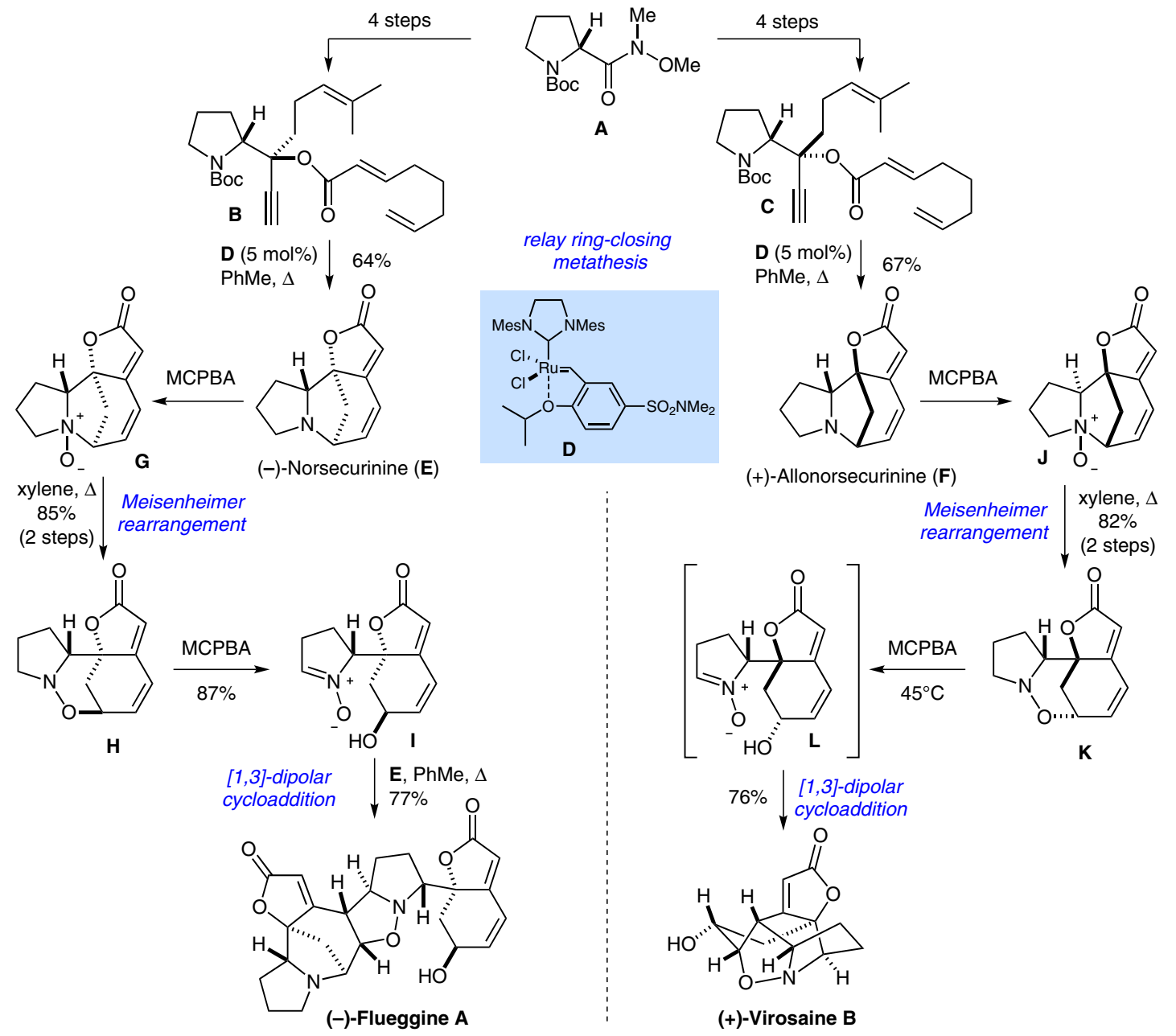

Gategory

Synthesis of Natural

Products and

Potential Drugs

Key words

dipolar

cycloaddition

relay ring-closing metathesis

[1,3]-sigmatropic rearrangement

Meisenheimer rearrangement

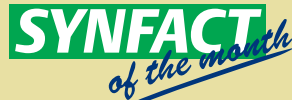

Significance: Securinega alkaloids have been used for a long time in traditional Chinese medicine. Two recently isolated members of this family, $(-)$-flueggine $A$ and (+)-virosaine $B$, have now been synthesized for the first time. The concise route to access the two natural products involves a $[1,3]$ dipolar cycloaddition. The precursors for this key step are synthesized by a sequence including a relay ring-closing metathesis followed by a Meisenheimer rearrangement.

SYNFACTS Contributors: Erick M. Carreira, Stefan Diethelm Synfacts 2013, 9(3), 0237 Published online: 15.02.2013 Dol: 10.1055/s-0032-1318189; Reg-No.: C00113SF
Comment: The route starts with the synthesis of the two natural products (-)-norsecurinine (E) and $(+)$-allonorsecurinine $(\mathbf{F})$ by a relay ring-closing metathesis, whereby the order of ring-closing events can be carefully controlled. The route then follows a previously described strategy (Tetrahedron 1993, 49, 8059) to access the two O-alkylhydroxylamines $\mathbf{H}$ and $\mathbf{K}$. Finally, heterodimeric (-)flueggine $A$ is accessed by allowing nitrone $\mathbf{I}$ to react with $\mathbf{E}$, whereas (+)-virosaine $B$ results from an intramolecular cycloadditon of nitrone $\mathbf{L}$. 